Editorial

\title{
Introduction to the Special Issue "Sport for Social Inclusion: Critical Analyses and Future Challenges"
}

\author{
Reinhard Haudenhuyse * and Marc Theeboom \\ Sport and Society Research Unit, Vrije Universiteit Brussel, 1050 Brussels, Belgium; \\ E-Mails: reinhard.haudenhuyse@vub.ac.be (R.H.), mtheeboo@vub.ac.be (M.T.) \\ * Corresponding author
}

Submitted: 15 June 2015 | Published: 25 June 2015

\begin{abstract}
"Sport for Social Inclusion: Critical Analyses and Future Challenges" brings together a unique collection of papers on the subject of sport and social inclusion. The special issue can be divided into three major parts. The first part consists of three papers tacking on a broad perspective on sport and social exclusion, with specific attention to austerity policies, sport-for-change and exclusion in youth sports. The second part of the special issue tackles specific themes (e.g., group composition and dynamics, volunteering, physical education, youth work, equality, public health) and groups (e.g., people with disabilities, disadvantaged girls, youth) in society in relation to sport and social exclusion. The third part consists of three papers that are related to issues of multiculturalism, migration and social inclusion. The special issue is further augmented with a book review on Mike Collins and Tess Kay's Sport and social exclusion (2nd edition) and a short research communication. The editors dedicate the special issue to Mike Collins (deceased).
\end{abstract}

\section{Keywords}

poverty; social exclusion; sport; youth

\section{Issue}

This editorial is part of the special issue "Sport for Social Inclusion: Critical Analyses and Future Challenges", edited by Dr. Reinhard Haudenhuyse (Vrije Universiteit Brussel, Belgium) and Professor Marc Theeboom (Vrije Universiteit Brussel, Belgium).

(C) 2015 by the authors; licensee Cogitatio (Lisbon, Portugal). This article is licensed under a Creative Commons Attribution 4.0 International License (CC BY).

\section{Poverty and Social Exclusion}

Specific groups of people in society are increasingly being faced with challenges on multiple (life) domains, such as education, employment, personal development, health, social participation and community integration. There is a broad range of definitions for social exclusion, and consequently social inclusion. Based on a scientific literature review Levitas et al. (2007) have defined social exclusion as: “...a complex and multidimensional process. It involves the lack or denial of resources, rights, goods and services, and the inability to participate in the normal relationships and activities, available to the majority of people in a society, whether in economic, social, cultural or political arenas. It af- fects both the quality of life of individuals and the equity and cohesion of society as a whole". From this definition Levitas et al. (2007) further derived a series of interacting domains and sub-domains. The identified domains and sub-domains are:

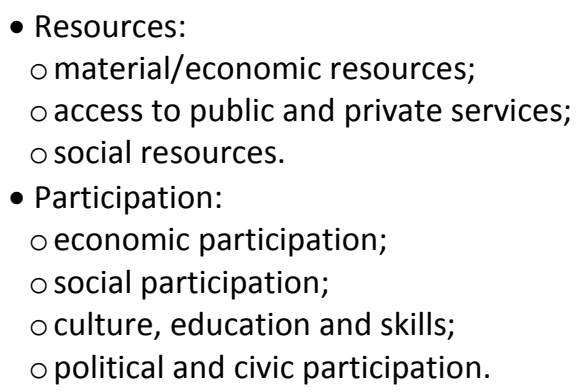


- Quality of life:

o health and well-being;

o living environment;

o crime, harm and criminalization.

Levitas et al. (2007) also refer to "deep exclusion" when exclusion manifests itself across more than one domain or dimension of disadvantage, resulting in severe negative consequences for quality of life, wellbeing and future life chances.

In their book Sport and social exclusion in global society, Spaaij, Magee and Jeanes (2014) challenge the "long held view" in sport sociology that poverty and material deprivation are at the core of social exclusion (see Collins \& Kay, 2014), by contending that social exclusion is a multidimensional set of processes that go beyond the lack of money. This position can however be criticized for confusing root causes and indeed multi-dimensional processes and outcomes of income related (monetary) poverty and its relationship with social exclusion. Levitas et al. (2007) have argued that there is overwhelming evidence that poverty is a major risk factor in almost all domains of exclusion. However, demonstrating causality in social science remains extremely difficult.

The concept of social exclusion is firmly entrenched in European government policy and has increasingly wide currency outside the European Union (EU) in international agencies such as the International Labour Office (ILO), United Nations, UNESCO and the World Bank. Specific policies and programs targeted at people have been set up in order to facilitate participation in employment and universal access to resources, rights, goods and services. Such "social inclusive" policies include, among others: preventing the risks of exclusion, helping the most vulnerable and mobilizing all relevant bodies in overcoming exclusion (Levitas et al., 2007) According to Spaaij et al. (2014), sport may be perceived as rather trivial and peripheral activity, but the role sport could play in promoting social inclusion has been increasingly embraced in international policy and research.

This special issue brings together a unique collection of papers on the subject of sport and social inclusion. The special issue can be divided into three major parts, which we will now briefly discuss.

\section{Structure}

In the first part we have three papers tacking on a broad perspective on sport and social exclusion. Mike Collins and Rein Haudenhuyse (United Kingdom, Belgium) describe the recent poverty trends in England, and identify groups that are more at-risk of being poor and socially excluded. They further describe a case study that addresses young people's social exclusion through the use of sports (i.e., Positive Futures) and argue that within a climate of austerity, sport-based social inclusion schemes are likely to become wholly inadequate in the face of exclusionary forces such schemes envision to combat. International renowned sport sociologist Fred Coalter (Ireland) takes on a skeptical view on the sport-for-change "movement". The dominance of evangelical beliefs and interest groups, who tend to view research in terms of affirmation of their beliefs, is restricting conceptual and methodological development of policy and practice. Coalter suggests that researchers need to adopt a degree of skepticism and need to reflect more critically on issues of sport, development and social inclusion. In the last paper of the first part Bethan Kingsley and Nancy Spencer-Cavaliere (Canada) investigate exclusionary practices in youth sports. In their paper they seek to understand sport involvement of young people living with lower incomes. Based on their findings Kingsley and Spencer-Cavaliere highlight a number of interconnected exclusionary processes in sport, which according to the authors demonstrate the need to reimagine sport in ways that challenge the hegemonic discourses continuing to exclude a large number of young people.

The second part of the special issue tackles specific themes and groups in society in relation to sport and social exclusion. Kim Wickman (Sweden) describes the experiences and perceptions of young adults with physical disabilities on sports. People with disabilities seldom get a chance to voice their opinions on their sport experiences. A deeper and gender-sensitive understanding of the context-related experiences of sport is according to Wickman a prerequisite for teachers and leaders to be able to provide adequate, inclusive and meaningful activities. Hebe Schaillée, Marc Theeboom and Jelle Van Cauwenberg (Belgium) examine the relationship between peer group composition in sport programmes and positive youth development of disadvantaged girls. Their results indicate that the extent to which disadvantaged girls derive benefits from their participation in sport depends on the group composition. In their contribution to the special issue, Mette Munk and Sine Agergaard (Denmark) examine how students' experiences of participation and nonparticipation in physical education are influenced by complex interactions within the group of students and in negotiations with teachers about the values and practices of physical education. The article argues that an understanding of the variety in students' participation or non-participation is important in terms of future intervention aimed at promoting inclusion processes in physical education. Evi Buelens, Marc Theeboom, Jikkemien Vertonghen and Kristine De Martelaer (Belgium) look at the underlying mechanisms and developmental experiences of a sport volunteering program for young people in socially vulnerable positions. The authors conclude that a systematic approach 
of the volunteer training program can play an important role in the development of competences of socially vulnerable youths both as a volunteer and an individual. As socially vulnerable youngsters participate less frequently in sports activities than their average peers, youth work organisations often try to guide the young people they reach to local sports clubs and inclusive sports activities. In relation to this subject Niels Hermens, Sabina Super, Kirsten Verkooijen and Maria Koelen (The Netherlands) describe factors relating to the organisation of intersectoral action among youth workers and local sports clubs that are preconditions for the success of this specific type of intersectoral action. In the final paper of the second part, Anna Aggestål and Josef Fahlén (Sweden) focus on how public health promotion is being constructed, implemented and given meaning within the Swedish Sport Confederation. Aggestål and Fahlén results indicate how discourses on democracy, equality and physical activity are used to legitimize the Swedish Sport Confederation role in public health. Also, how these discourses pose challenges for organized sport in meeting objectives of public health.

The third part of the special issue consists of three papers that are related to issues of multiculturalism, migration and social inclusion. Jorge Moraga (USA) paper pushes beyond the black-white binary in an effort to expand understandings into the relationship between sport, Latinidad, and global capitalism in the 21st century. Moraga makes the case that while the National Basketball Association (NBA) may be another example of browning the sporting gaze, the gaze remains fixed upon Western capitalist notions of identity and representation. Kyle Rich, Laura Misener and Dan Dubeau (Canada) discuss a participatory sport event which seeks to connect newcomers to Canada (recent immigrants and refugees) in order to build capacity, connect communities, and facilitate further avenues to participation in community life. With their study, the authors aim to unpack the complex process of how inclusion may or may not be facilitated through sport, as well discussing the role of the management of these sporting practices. Gamal Abdel-Shehid and Nathan Kalman-Lamb (Canada) explore the efficacy of sport as an instrument for social inclusion through an analysis of the film "Bend it Like Beckham". According to AbdelShedid and Kalman-Lamb, the version of multiculturalism offered by the film is one of assimilation to a utopian English norm. Such a conceptualization falls short of conceptions of hybrid identity that do not privilege one hegemonic culture over others.

The special issues is augmented with a book review and a short research communication. In "Sport, social exclusion and the forgotten art of researching poverty" Rein Haudenhuyse (Belgium) critically reviews Mike Collins and Tess Kay's second edition (2014) of their seminal and ground-breaking work on Sport and Social
Exclusion (2003). Last but not least, Daniel Parnell, Andy Pringle, Paul Widdop and Stephen Zwolinsky (UK) insightfully discuss a partnership between an academic institute and a third sector organisation attached to a professional football club in the United Kingdom. The partnership concerns a sport for development intervention. Through this case study, the authors elaborate on the development of third sector-university partnerships and the use of intervention mapping to meet shared objectives in relation to articulating the impact of interventions to funders and for research outputs.

\section{Dedication to Mike Collins}

We would like to dedicate "Sport for Social Inclusion: Critical Analyses and Future Challenges" to Mike Collins who passed away in the summer of 2014. Mike Collins was a Senior Lecturer in Recreation Management at Loughborough University for over ten years before "retiring" to part-time work in Sports Development and Faith Communities at the University of Gloucestershire. Prior to holding this position he founded and directed the Institute of Sport and Recreation Planning and Management at the same university for five years. He was Head of Research Strategy and Planning at the Sports Council from its founding, and active in the Council of Europe and what is now the Countryside Recreation Network. He then became Professor of Sports Development at the University of Gloucestershire.

Mike Collins was the first author to submit a paper proposal for the special issue and personally contacted us and inquired about the scope of the special issue. Mike was then already hospitalized, in his terminal phase, which is a testament of his strong dedication and personal commitment-even in personal times of sickness and hardship - to those groups and individuals in society that are time and time again denied access to sport, leisure and so many others domains in society. Groups and individuals that are the first in line to bear the brunt of austerity measures across the whole of Europe (and beyond). In relation to this, Clarke and Newman (2012) have pointed out that the economic crisis has not been caused by public spending, but by the greed of bankers and gambling-like cultures of financial centres and political elites, which were in the end bailed out by public money. Problematically, spending cuts within an austerity regime impinge directly on the poor, the sick and the disabled (Levitas, 2012). Including their sport and leisure participation.

It is only fitting that we give Mike Collins (2014, p. 253) the last words:

The sports world can leave inclusion to others and be part of the problem of an unequal society, or take hard decisions and demanding steps to be part of the moves to inclusion and be part of the solution. 


\section{Conflict of Interests}

The authors declare no conflict of interests.

\section{References}

Clarke, J., \& Newman, J. (2012). The alchemy of austerity. Critical Social Policy, 32(3), 299-319.

Collins, M., \& Kay, T. (2003). Sport and social exclusion. London: Routledge.

Collins, M., \& Kay, T. (2014). Sport and social exclusion (2nd Ed.). London: Routledge.

Levitas, R., Pantazis, C., Fahmy, E., Gordon, D., Lloyd, E. \& Patsios, D. (2007). The multi-dimensional analysis of social exclusion: A report for the social exclusion task force. London.

Levitas, R. (2012). The just's umbrella: Austerity and the big society in coalition policy and beyond. Critical Social Policy, 32(3), 320-342.

Spaaij, R., Magee, J., \& Jeanes, R. (2014). Sport and social exclusion in global society. New York: Routledge.

\section{About the Authors}

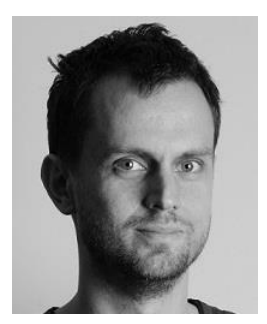

\section{Dr. Reinhard Haudenhuyse}

Reinhard Haudenhuyse has a Master's degree in Physical Education. He holds an additional Master's degree in Conflict and Development (Third World Studies). In 2012, Reinhard received his PhD, entitled "The Potential of Sports for Socially Vulnerable Youth", in Physical Education and Movement Sciences at the Vrije Universiteit Brussel. His work focuses on the impact of sport on an individual, group and societal level, with specific attention to people living in disadvantaged and precarious situations.

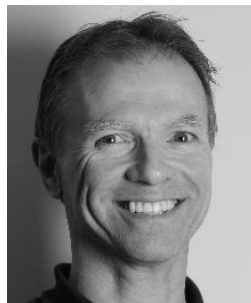

\section{Prof. Dr. Marc Theeboom}

Marc Theeboom holds a PhD in Physical Education and a Master's degree in Leisure Studies. He works as a full professor at the Vrije Universiteit Brussel, Belgium (VUB). He is chair of the "Sport and Society" Research Group and of the Department of Sport Policy and Management. Since 2010, he has been the promoter-coordinator of the Flemish Policy Research Centre for Sports (Steunpunt Sport). His research primarily focuses on policy-related and pedagogical aspects of sport in general as well as in relation to specific target groups in particular. 